\title{
Ю.Ю. Черноскутов
}

\section{РАЗВИТИЕ ТЕОРЕТИЧЕСКИХ И ТЕРМИНОЛОГИЧЕСКИХ ОСНОВАНИЙ СЕМАНТИКИ В ЛОГИКЕ И ФИЛОСОФИИ XIX BEKA ${ }^{1}$}

\begin{abstract}
Рассматривается процесс развития английской и немецкоязычной семантических теорий в XIX в.: изменения традиционной теории сигнификации в логике Р. Уэтли и Дж.С. Милля; как немецкие переводы логики Милля и Британских философов привели к появлению системы семантических терминов, не являвшейся прямым аналогом английской терминологии; некоторые результаты семантических исследований в школе Брентано - рецепция Британских теорий в диссертации А. Мейнонга и лингвистическая теория значения А. Марти.

Ключевые слова: сигнификация, значение, Милль, Мейнонг, Марти, Фреге.
\end{abstract}

\section{Введение}

Основания современной семантической теории именования заложены усилиями Э. Шрёдера, Э. Гуссерля и Г. Фреге едва ли не одномоментно, в работах, опубликованных в течение 1890-1892 гг. Они удивляют разнообразием толкования используемой терминологии. В предлагаемой здесь статье мы предприняли попытку проследить истоки и причины появления такого смыслового разброса, а также концептуальных предпосылок самих этих теорий в процессе ассимиляции Британских теорий именования немецкой философией.

\section{1. Теория сигнификации в английской логике}

Проблемы семиотики всегда занимали важное место в Британской философии Нового Времени. Основным термином здесь была «сигнификация». Это был максимально общий термин, допускавший различные толкования и споры по их поводу, «обозначаемое» вообще. Основной вопрос, связанный с сигнификацией, состоял в том, является ли сигнификацией имени предмет или идея в сознании. Большинство авторов, включая Д. Локка, Дж. Беркли и Д. Юма, делали выбор в пользу второго. Наиболее тщательно этот комплекс проблем был исследован Локком, и его теории долгое время служили определяющим контекстом исследований на эту тему. Хотя в дальнейшем мы будем иногда ссылаться на некоторые из его положений, подробный анализ философии семиотики Локка остается за рамками нашего исследования. В качестве введения в нее и в наше дальнейшее повествование с ней можно ознакомиться в $[1,2]$.

В начале XIX в. данная проблематика усилиями Р. Уэтли и Дж.С. Милля была импортирована в логику. Как нами уже отмечалось в [3, 4], Британская традиция изложения логики видела предмет логики в рассуждении, которое

\footnotetext{
${ }^{1}$ Исследование выполнено при поддержке РФФИ, грант № 18-011-00895.
} 
осуществляется в языке. Поэтому вопрос о значении языковых единиц, из которых состоит рассуждение, возникал естественным образом: логические законы и принципы приходилось разъяснять и обосновывать в терминах содержания языковых выражений. Это обусловило некоторые важные изменения, которые были внесены логиками в традиционные для Британской философии способы постановки и методы решения семантических проблем.

\section{1. Ричард Уэтли: сигнификация и класс}

Уэтли, книга которого «Элементы логики» вызвала возрождение логических исследований в Британии, не только приводит в логику семиотику Британских эмпиристов, но и возрождает тот традиционный номинализм, который господствовал в позднесхоластическом Оксфорде. Он безоговорочно отвергает мнение, что логика занимается мышлением и абстрактными идеями. Эта наука, убежден Уэтли, имеет дело только с языком: «Я вынужден признаться, что ничего не знаю об этих ,,абстрактных идеях“ или каких-либо „универсалиях“, кроме их Знаков» ${ }^{1}$ [5. Р. 46]. Соответственно, логика Уэтли строится не из понятий или представлений, но из имен и их значений.

Из старых схоластических делений он считает важным для логики только деление имен на общие и единичные. Для описания их свойств он использует термины «сигнификация» и «денотация», иногда «десигнация». Он не приводит разъяснений по поводу смысловых различий между ними, и, даже опираясь на контекст употребления, не всегда можно понять, в чем состоит это различие и есть ли оно вообще. Как мы сейчас увидим, склонность не различать смыслы этих терминов легко объяснима. Сигнификация единичного имени состоит в том, что оно замещает одного индивида. Общее имя может делать это с несколькими индивидами, поскольку «охватывает их одной сигнификацией» и потому приложимо к каждому из таких индивидов или обозначает любого из них. Он дважды описывает это различие, но в одном месте выражает отношение между именем и индивидом (или индивидами) глаголом stand for [6. Р. 60], а в другом - denote [Ibid. C. 47]. Самих же индивидов он называет «сигнификатами» [5. Р. 88; 6. Р. 61]. Казалось бы, естественно выражаться так, что имена денотируют денотаты, но сигнифицируют сигнификаты, однако в книге Уэтли они денотируют сигнификаты. Подобное словоупотребление неудивительно, если учесть резкую аллергию автора на любые абстракции. По этой причине ему остается говорить только об индивидах, а к ним удобней прилагать более конкретное «денотиривание», чем слишком общее «сигнифицирование». Поэтому из всех возможных видов сигнификации Уэтли затруднительно было бы найти что-либо, помимо денотации; различение этих терминов не имеет под собой реальной почвы.

Уэтли, насколько можно судить, впервые импортирует в логику понятие класса. В первом издании он не считает нужным разъяснять, что имеется в виду под классом, такое определение появляется лишь позднее. «Под словом «класс» разумеется не только «общее понятие», или «совокупность общих признаков», или «общее описание», под которое действительно подходят многие предметы, но такое, под которое можно мысленно подвести неопре-

\footnotetext{
${ }^{1}$ Здесь и далее при ссылках на оригинальный текст перевод выполнен мной. - Ю.Ч.
} 
деленное число предметов, а именно столько предметов, сколько (говоря разговорным языком) их может «подойти под описание»» [7. С. 74-75]. В привычных нам ныне терминах понятие класса невозможно охарактеризовать как экстенсионал или интенсионал. Он употребляется для указания на индивиды, но понимается как общее описание с помощью атрибутов. Такое понимание класса впоследствии долгое время воспроизводится и другими Британскими логиками.

Уэтли, воспроизводя номиналистские установки, как мы уже указывали, изначально отвергает какие-либо реально существующие абстрактные идеи. Поэтому общим именам не соответствует ничего, что могло бы напоминать о каких-либо абстрактных или идеальных сущностях. Общему имени соответствует только класс индивидов. Различие между родом и видом, например, состоит только в том, что первое имеет более экстенсивную сигнификацию, чем второе. Это находит отражение и в его теории общих имен: семантического звена, подобного Фрегевскому «смыслу» или субъективным идеям / представлениям, им принципиально не допускается. Имя «гора» не предполагает реального существования горы вообще, оно не обозначает никакой абстракции. Такое имя просто выражает неполное или неадекватное понятие об Этне, или Эльбрусе, или любой другой индивидуальной горе. Словами самого автора, «понятие, выраженное общим термином, есть просто неадекватное (или неполное) понятие об индивиде; и из-за самого обстоятельства своей неадекватности оно равно успешно приложимо к любому из нескольких индивидов» [5. Р. 77; 6, Р. 49-50, 67]. При желании здесь можно усмотреть смутное предвосхищение идеи Фреге об имени понятия как неполном и ненасыщенном, но в радикально номиналистском исполнении .

Это различие общих и единичных имен важно для логики прежде всего потому, что играет роль при построении высказываний (propositions). Общее имя, благодаря приложимости к классу индивидов, имеет свойство предицируемости: оно без ограничений может утвердительно утверждаться о других терминах. Единичное же имя в общем случае такого свойства не имеет: оно не может выступать в качестве предиката высказывания, за исключением двух случаев: во-первых, в отрицательных высказываниях, во-вторых, в случае равенства терминов субъекта и предиката, или, словами Уэтли, «если субъект и предикат были только двумя выражениями одного и того же индивидуального объекта» [5. Р. 76].

Уэтли использует значения имен для объяснения логических принципов, но не предлагает отдельной теории сигнификации и других семантических терминов. Он использует их как будто в силу необходимости, как нечто само собой разумеющееся, поскольку без этих слов невозможно обойтись.

\section{2. Дэкон Стюарт Милль: сигнификация и смысл}

В «Системе логики» Дж.С. Милля некоторые семантические понятия становятся предметом отдельно и целенаправленно разрабатываемой теории. Если Уэтли просто привлек эту семантическую методологию в современную логику, то Милль может считаться основателем теории именования, поскольку осознанно сделал ее фундаментом философии логики и последовательно построил логику на этом фундаменте. Он явно фиксирует, что, поскольку рассуждение может совершаться только при помощи слов, логические прин- 
ципы должны излагаться в терминах содержаний языковых выражений. Обоснованию этого подхода посвящена вся первая глава книги, которая так и озаглавлена: «О необходимости начать с анализа языка». В последнем параграфе этой главы дается категоричное заключение: «Сигнификация имен и общее отношение между именами и сигнифицируемыми ими вещами должна занимать первое место в предпринятом нами исследовании» [8. Р. 24]. Исследованию этого посвящена вторая глава, «Об именах».

Семантическая теория Милля, казалось бы, достаточно проста и прозрачна, ей посвящено и продолжает посвящаться достаточное число исследований. Тем не менее в ней есть тонкости и неоднозначности, некоторые важные термины остаются без определений и разъяснений, употребляются в разных смыслах, в том числе и противоречивых. Но по порядку.

На основной вопрос Британской семиотики Милль, как и Уэтли, дает номиналистический и антилокковский ответ: имена являются именами вещей, но не наших идей о вещах. Вот известная цитата, без которой не обходится ни одно изложение семантической теории Милля: «Говоря „солнце причина дня“, я не хочу сказать, что моя идея солнца причиняет или возбуждает во мне идею дня... Я хочу сказать, что известный физический факт, который называется присутствием солнца... производит другой физический факт, называемый днем» [9. С. 29]. Заметим, что в этой известной цитате, как и во всем содержащем ее двухстраничном первом параграфе, не встречается ни слово «сигнификация», ни какой-либо другой семантический термин. Милль постоянно использует здесь оборот «the name of».

В дальнейшем традиционное различение предмета и идеи нигде не вспоминается. Уяснив, что имена относятся только к предметам, Милль вновь начинает использовать слово «сигнификация», но, на мой взгляд, для того, чтобы характеризовать не виды обозначаемого - с ними все ясно, это предметы и только предметы, - но способы, какими имя указывает на эти предметы. Иначе говоря, в связи с семантической теорией Милля уместней говорить не о видах сигнификации, но о способах сигнификации.

Во всяком случае, когда речь идет о самой известной части теории Милля, касающейся различения коннотативных и неконнотативных имен, это представляется несомненным. Она излагается в пятом параграфе второй главы. Здесь он выделяет два способа сигнификации: денотацию (прямое указание на предмет или атрибут) и коннотацию (указание на них же через атрибут или атрибуты, подразумеваемые в имени). Денотация является прямой, а коннотация - косвенной сигнификацией. В зависимости от того, какой сигнификацией обладают имена, они могут относиться к одному из двух видов: во-первых, имена, обладающие только денотацией - к ним относятся имена собственные; во-вторых, имена, обладающие не только денотацией, но и коннотацией.

У Милля появляется еще одна важная характеристика имени - его смысл (meaning). Милль не разъясняет, что он под этим имеет в виду, но из тех ситуаций, где он ставит о вопрос о смысле и как он на него отвечает, можно вывести, что смысл для него - это, во-первых, информация, которую сообщает имя, и, во-вторых, то, благодаря чему мы можем понимать и познавать имена. Действительно, слово «смысл», которое изредка появлялось в тексте и раньше, часто как синоним сигнификации, начинает систематически исполь- 
зоваться, когда Милль обращает внимание на особый вид имен, которые после Рассела стали называться дескриптивными. Эти имена, как и собственные, являются единичными, но, в отличие от них, представляют собой еще один вид коннотативных имен. В контексте этих разъяснений выясняется, что собственные имена не только не-коннотативны, но и неосмысленны (unmeaning), потому что только показывают, «о каком именно предмете мы говорим, но не сообщая о нем ничего» [8. Р. 41]. Дескриптивные же имена единичны, потому что частью их смысла является то, что набору атрибутов соответствует только один индивид (первый Римский император), или потому что некоторое общее имя так ограничивается другими словами, что может, не противореча cмblслу составного имени, предицироваться только об одном индивиде (нынешний премьер-министр Англии). Словом, единичность таких имен «выявляется из их смысла» [Ibid. Р. 42].

Таким образом, хотя имена предназначены для того, чтобы называть предметы, их смысл Милль усматривает не в денотации, а в коннотации. «Как скоро имена, данные объектам, сообщают какую-либо информацию, т.е. как скоро имеют сами по себе смысл (meaning), то смысл этот заключается не в том, что они денотируют, а в том, что ими коннотируется». Поэтому собственные имена, по убеждению Милля, представляют собой лишь бессмысленные метки (unmeaning mark), предназначенные только для того, чтобы выделить предмет для внимания, отличить его от других предметов. Имена «Софрониск» и «отец Сократа» - имена одного индивида, но они имеют разный смысл.

Собственно, нетрудно заметить, и многими уже отмечалось, что «смысл» (meaning) Милля по многим важным характеристикам достаточно близко соответствует «смыслу» (Sinn) Фреге. Но я бы хотел указать на одно принципиальное различие: фрегевская пара «Sinn-Bedeutung» возвращается к традиционному членению в области обозначаемого, а у Милля разделение смысла (идентифицируемого с коннотацией) и денотации относится не к обозначаемому, но к способу обозначения.

Необходимо отметить, что в довольно обширной литературе, посвященной теории именования Милля, различение сигнификации и смысла игнорируется. По крайней мере мне нигде не удалось его обнаружить. Дело в том, что, в отличие от денотации и коннотации, Милль так и не дал каких-либо разъяснений, что же он понимает под сигнификацией и под смыслом. Буквальное прочтение, кажется, не может не создать впечатления, что Милль понимает и использует эти слова как синонимы. Но, на мой взгляд, он просто употребляет слово «сигнификация» в разных смыслах.

Слово «смысл», как мы заметили, он начинает активно употреблять, когда ему понадобилось объяснить различие между собственными и дескриптивными именами. После этого в течение одной-двух страниц смысл словно поглощает сигнификацию: в начале соответствующих разъяснений он характеризует собственные имена как неосмысленные (unmeaning), а заканчивает тем, что они «строго говоря, не имеют никакой сигнификации» [Ibid. P. 43]! А на следующей странице говорится, что слова, сообщающие новую информацию, представляют собой, в отличие от собственных имен, «не просто метки, но нечто большее, это сигнификантные метки; и их сигнификанс образован коннотацией» [Ibid. P. 44]. Но оба эти утверждения, что собственные 
имена не имеют сигнификации и что сигнификация состоит в одной только коннотации, прямо противоречат всему, что он говорил об этом на предыдущих страницах пятого параграфа. А говорилось там, что денотация - это прямая сигнификация, т.е. вид последней, что неконнотативные имена сигнифицируют только предмет или только атрибут, но ведь сигнифицируют! Такое ощущение, что где-то на с. 42 незаметно произошла подсознательная революция, и Милль начал отождествлять всю сигнификацию только со смыслом и коннотацией. Или наоборот, учитывая прецеденты нечеткого словоупотребления в остальных местах трактата, на первых страницах пятого параграфа произошло временное торжество другой революции, сигнификация ненадолго стала обозначать нечто большее, чем только смысл, за это время Милль успел построить теорию денотации и коннотации, после чего сигнификация опять стала смыслом и свелась к одной только коннотации.

Таким образом, Милль не дал четкого определения понятиям сигнификации и смысла, что ставит перед нами интерпретативную проблему. Мы вынуждены выбирать между двумя стратегиями. Либо сигнификация и смысл действительно взаимозаменимые синонимы, тогда излагаемая на первых страницах пятого параграфа теория двух способов сигнификации противоречит самому смыслу слова «сигнификация». Либо признать, что текст «Системы логики» позволяет осуществить две реконструкции теории сигнификации, и в рамках второй из них последняя не совпадает с понятием смысла. Мне представляется более естественным выбрать второе, причем соответствующую вторую реконструкцию принять в качестве основной. Тогда мы сохраняем без противоречий теорию двух способов сигнификации и будем вынуждены согласиться, что «смысл» является самостоятельной категорией в семантике Милля. При этом также придется иметь в виду, что во многих других местах книги, кроме первых пяти страниц пятого параграфа второй главы, слово «сигнификация» используется в другом, более узком смысле.

\section{3. Рецепция теории сигнификации в немецкоязычной философии}

В германской философии семантическая проблематика долгое время оставалась в лучшем случае на периферии, а то и вовсе не вызывала интереса. Ситуация резко изменилась, насколько можно судить, после перевода трудов Британских философов на немецкий язык. Причем воздействие Британской философии происходило в Германии по двум каналам. Во-первых, это перевод «Системы логики» Дж.С. Милля. Он был издан в 1849 г. - всего через шесть лет после выхода оригинала, а в 1868 г. появилось уже его третье издание, которым пользовались Фреге и Шрёдер. Во-вторых, это третье издание вошло в своеобразный резонанс с публикацией переводов основополагающих трудов классиков Британской философии Нового времени. В 1868 г. появился первый немецкий перевод «Трактата о принципах человеческого познания» Дж. Беркли, выполненный Фридрихом Ибервегом, затем в 1869 г. выходит «Трактат о человеческой природе» Д. Юма, а в 1872 - «Опыт о человеческом разумении» Дж. Локка, переведенные Юлиусом Кирхманом. Последние два труда издавались в немецком переводе еще в XVIII в., в 1755 и 1757 гг. соответственно, когда немецкий философский язык находился в стадии формирования, поэтому переводы Кирхмана фактически заново ввели их в обиход 
немецкой философской мысли. Поэтому, когда в конце 1860-х гг. почти одновременно появились переводы трактатов Беркли и Юма, немедленно вслед за ними начали одна за другой издаваться посвященные им монографии, статьи, защищаться диссертации. Так, уже в 1870 и 1871 гг. вышли две монографии Фредерикса о философии Беркли, 1871 и 1872 гг. две монографии Йодля, а в 1874 г. - Пфляйдерера, посвященные философии Юма.

Наконец, важную роль в росте интереса к Британской философии сыграло вышедшее в 1875 г. второе издание книги Куно Фишера «Фрэнсис Бэкон и его последователи». Текст был значительно расширен и дополнен по сравнению с первым изданием 1856 г., фактически это была другая книга, в два раза превосходившая первое издание по объему. В числе прочего было добавлено и подробное освещение учений Локка и Беркли о значении имен. Это исследование К. Фишера достойно внимания уже потому, что его лекции по логике и истории философии в Йенском университете слушал в 1869/70 г. молодой студент Готтлоб Фреге.

Немецкий перевод «Системы логики» Дж.С. Милля имел по крайней мере одну содержательную особенность, сыгравшую, как мне кажется, важную роль в том развороте, который несколько позднее произошел с семантическими исследованиями в немецкоязычной философии. Речь идет о переводе некоторых ключевых терминов - тех самых, на неопределенность значения которых в книге Милля мы обратили внимание в предыдущем разделе.

Дж.С. Милль, как мы там отметили, не приводит точных разъяснений по поводу того, что понимает под смыслом, а что под сигнификацией, и нетрудно найти места, где он употребляет их как синонимы. Тем не менее не только в его «Системе логики», но и в более широком контексте англоязычной философской литературы достаточно очевидно, что эти два термина несут разную смысловую нагрузку и выполняют разные функции. Сигнификация - достаточно нейтральный термин, выражающий обозначаемое в самом общем и широком смысле. В качестве видов сигнификации могут рассматриваться не только денотация и коннотация, но и референция и, наконец, сам смысл. Смысл (meaning) систематически ассоциируется с информацией, сообщаемой именем, с тем, что имя выражает результат неких познавательных усилий.

Тем не менее переводчик «Системы логики» на немецкий язык не придал значения этим тонкостям, вследствие чего и signification, и meaning постоянно, за единичными исключениями, переводятся как Bedeutung ${ }^{1}$. В результате у немецкого Милля «Bedeutung» стал всеохватывающим семантическим термином [10]. Именно такую логику Милля имели перед собой Шрёдер, Гусерль и Фреге.

В упомянутых переводах философских трактатов, выполненных Ибервегом и Кирхманом, meaning всегда передается как Sinn, благодаря чему немецкий читатель улавливал смысловое различие, соответствующее различию между смыслом и сигнификацией. Но, с другой стороны, сам термин

\footnotetext{
${ }^{1}$ Стоит заметить, что аналогичная ситуация наблюдается и в русском переводе [9]. Кажется, что выбор слов «смысл», «значение», «содержание» и тому подобных для передачи любого из слов «signification», «sense», «import» и других произволен и продиктован только стилистическими соображениями.
} 
«signification», как и производные от него слова, они не стремились переводить единообразно, передавая его то как Bezeichnung, то как Bedeutung. Больше того, Ибервег постоянно передает часто используемое Беркли denote с помощью того же bezeichnen.

А если мы добавим сюда, в каких терминах излагал учения Британских философов К. Фишер, то картина еще больше усложнится. Тот тоже описывает связь между словом и представлением, т.е. сигнификацию, обоими словами: то с помощью Bezeichnung, то с помощью Bedeutung; плюс к тому для общего указания на содержания и назначения слов Фишер использует слова «Geltung» и «Wert» [11. S. 592-600, 705-707]. Словом, если у кого-то затеплится надежда установить стандартные соответствия между традиционными британскими и новоизобретавшимися немецкими семантическими терминами, то его ждет неизбежное разочарование.

Это было усилено общей тенденцией национального романтизма, овладевшей умами многих философов и ученых, когда многие стремились выработать национальную терминологию, часто отказываясь от общепринятых терминов латинского и греческого происхождения. Например, Фреге предпочитал не использовать даже такие привычные логические термины, как «импликация», «дедукция», «модус поненс», «контрапозиция» и др., используя, а иногда и изобретая вместо них слова немецкого происхождения. Все это привело к тому, что в немецкой логико-философской литературе была вытеснена на периферию традиционная семантическая терминология, а вместе с ней подчас и стоявшие за этими терминами концепции и проблемы. В результате перевода трудов британских логиков и философов на немецкий язык фактически сформировались предпосылки для появления новой системы семантических терминов, которая не имела точного соответствия с английским первоисточником.

\section{2. Теория именования в школе Брентано}

Одна только описанная выше деформация в переводах едва ли могла бы стать исчерпывающей причиной тех новых подходов к разработке семантической проблематики, которую мы встречаем в 1890-е гг. в трудах немецких логиков. Не менее важную роль сыграло то, как заимствованные семантические теории соединились с некоторыми традиционными концепциями немецкоязычной логики и философии языка, в частности с некоторыми установками школы Брентано. Во второй части рассмотрим некоторые особенности теории именования в работах двух представителей этой школы А. Мейнонга и А. Марти.

\section{1. Алексиус Мейнонг: сигнификация в терминах объема и содержсания}

В первой опубликованной работе А. Мейнонга «Юм-штудии І. К истории и критике английского номинализма» (1877), которая содержит текст его докторской диссертации, можно увидеть лишь крайне слабые намеки на созданную им значительно поздней теорию предмета. По этой причине она вызывает незначительный интерес исследователей. Мы можем указать лишь посвященные ей статьи К. Барбера $[12,13]$, а также исследования Р.Д. Роллингера [14]. Диссертация посвящена проблеме абстрактных и общих 
идей в британской философии, прежде всего у Беркли и Юма. Он тщательно анализирует аргументы этих авторов, пытаясь найти в них слабые и сильные места, с позиций дескриптивной психологии Брентано.

Как мы уже знаем, Британскими философами Нового Времени, как и логиками в XIX в., вопрос о сигнификации имени ставился с той предпосылкой, что значением имени следует считать либо предмет, либо идею. Но никогда в качестве кандидата не обсуждалась пара объем / содержание (экстенсионал / интенсионал) - Британская логико-философская традиция долгое время просто не знала соответствующего учения. Несмотря на кажущееся сходство, предмет или класс предметов, очевидно, не тождественны экстенсионалу континентальной логики, как и индивидуальная идея (представление) не тождественна содержанию понятия.

Кажется, первую попытку если не прямого отождествления сигнификации с экстенсионалом и / или интенсионалом, то по крайней мере интерпретации соответствующей проблематики в этих терминах мы встречаем в упомянутой работе Мейнонга. Он прибегает к такой интерпретации уже на второй странице диссертации, анализируя отрывок из Локка, где последний проводит мысль, что общая идея треугольника невозможна, потому что она «не должна быть идеей ни косоугольного, ни прямоугольного, ни равностороннего, ни равнобедренного, ни неравностороннего треугольников; она должна быть всеми ими и ни одним из них в одно и то же время». Как следствие, заключает Локк, «не может существовать идея, в которой соединены части нескольких различных и несовместимых друг с другом идей» [15. Т. 2. C. 74]. Мейнонг указывает, что Локк приходит к такому странному заключению из-за того, что путает объем и содержание понятия (на это уже обращал внимание Роллингер [14. Р. 35-36]). И в дальнейших рассуждениях он то и дело излагает выкладки Локка, Беркли и Юма в терминах объема и содержания представлений, стремясь с их помощью прояснить, а местами и усовершенствовать теории этих авторов. Непосредственно после указанного замечания о путанице у Локка он переходит к разбору аргументов Беркли, который, с одной стороны, отвергал абстрактные идеи Локка, но, с другой стороны, отстаивал существование общих идей. При этом один из ключевых моментов анализа Мейнонга состоит в том, что абстрактное характеризует содержание представления, а общее - его объем [16. С. 200]. Поэтому рассматривая рассуждения Беркли, утверждает Мейнонг, мы вынуждены переходить «от вопроса о содержании понятия к вопросу о его объеме» [16. S. 198]. Кроме того, в соответствии с пониманием, возобладавшим в Австрийской логической традиции еще до пришествия Брентано, он понимает под объемом понятия не совокупность подчиненных ему видов, но совокупность подпадающих под него индивидов [Ibid. S. 211]. Благодаря такой интерпретации объема понятия его отождествление с предметами как сигнификатами общего имени происходит довольно просто и даже естественно, если и не провозглашается явно.

Если иметь в виду эти наблюдения, смысл и мотивы усилий Мейнонга по интерпретации и улучшению теорий значения Британских философов становятся более прозрачными и объяснимыми. Локк видит сигнификацию общего имени (Мейнонг, видимо, следуя переводам Ибервега и Кирхмана, передает 
это то как Bezeichnung, то как Bedeutung ${ }^{1}$ ) в абстрактной идее, но ни в коем случае не в предмете. Для Беркли слово является общим не в силу неких собственных особенностей, но потому, что соответствующая ему частная идея используется для указания на все подобные ей другие частные идеи. (При желании в этом рассуждении Беркли можно усмотреть предвосхищение принципа квантификации свободной переменной.) Фактически за рассуждениями Мейнонга стоит не всегда явно проговоренная, но довольно прозрачная мысль, что Локк смотрел на сигнификацию как на интенсионал, а Беркли - как на экстенсионал. Поскольку же для него, как для человека, воспитанного в континентальной логико-философской традиции, эти две характеристики неотделимы друг от друга, достаточно естественно, что он, завершая часть исследования, посвященную Беркли, делает вывод, не встречавшийся ни у одного Британского автора. Он ставит под сомнение целесообразность сведения сигнификации имени к одной из двух сторон: «Утверждать, что слова обозначают [bezeichnen] только предметы было бы столь же однобоко, как и утверждать, что они обозначают только идеи. Скорее, они делают и то и другое, хотя, необходимо отметить, в разном смысле» [16. S. 214]. Насколько можно судить, это первый зафиксированный в литературе прецедент, когда пересаженная на немецкоязычную почву британская теория сигнификации претерпевает подобную трансформацию. Тут возможно возражение, что подобный радикальный пересмотр был совершен уже Миллем, но следует вспомнить, что его денотация и коннотация относятся не собственно к обозначаемому, но к способам обозначения.

Поскольку такой подход к пониманию семантики имени стал для нас привычным благодаря статье Фреге «О смысле и значении», можно поставить вопрос о том, не был ли Фреге знаком с этой работой Мейнонга. Прямого и однозначного ответа на него мы дать не можем. Нет никаких подтверждений, что Фреге знакомился с текстом диссертации Мейнонга. Но можно отметить по крайней мере один любопытный факт. Мейнонг, анализируя теорию абстракции Милля, рассуждает о равенстве и тождестве и при этом указывает, что только ограниченность языка заставляет нас говорить, что $a$ и $b$ имеют «одно и то же» свойство Ф там, где вполне можно говорить, что свойство Ф предмета $a$ «равно» свойству Ф предмета $b$ (переменные здесь введены мною для удобства пересказа, изложение Мейнонга обходится без них). А это значит, что только особенности используемого нами языка заставляют нас усматривать тождество там, где имеет место равенство [Ibid. S. 205]. Почти такой же ход мысли мы встречаем в $\$ 65$ «Оснований арифметики» Г. Фреге. В рассуждениях, предваряющих определение численности через абстракцию, Фреге замечает: «Хотя, как кажется, „один и тот же“ выражает полное совпадение, а ,равный“ - только совпадение в том или ином отношении; можно тем не менее принять такое прочтение, которое упразднит это различие, если, например, вместо „расстояния равны по длине“ говорить

\footnotetext{
${ }^{1}$ Цитаты из британских авторов приводятся Мейнонгом в немецком переводе, но в примечаниях делаются ссылки на оригинальные английские заголовки их трактатов без указания на издания и номера страниц, а только на номера глав и параграфов. Немногие приводимые им цитаты из Локка заметно отличаются от того, как они переведены в издании Кирхмана. Либо Мейнонг пользовался неустановленным мной переводом, либо переводил эти отрывки самостоятельно. Цитаты же из Беркли отличаются от содержащихся в переводах Ибервега лишь несущественными стилистическими или грамматическими расхождениями.
} 
„длина расстояний равна“ или „одна и та же“; вместо „пятна равны по цвету“ „цвета пятен равны“"» [17. S. 73-74]. Мейнонг возвращается к этой мысли во второй части своих исследований, «Нume Studien II», вышедшей через пять лет и посвященной теории отношений. Там этот ход мысли воспроизводится и излагается более развернуто: отношению тождества посвящена отдельная, седьмая глава [18. S. 707-713]. Вскоре рецензию на это исследование Мейнонга опубликовал А. Хёфлер в седьмом томе ежегодного журнала «Ежеквартальник научной философии» за 1883 г., т.е. за год до появления упомянутого труда Фреге. В этой рецензии Хёфлер достаточно подробно воспроизводит соответствующие рассуждения Мейнонга, приводя пространные цитаты [19. S. 489-490]. То, что Фреге регулярно знакомился с публикациями этого журнала и отправлял туда некоторые свои работы, не является секретом ${ }^{1}$. Нам не известно никаких свидетельств того, что Фреге читал эту рецензию Хёфлера, тем более свидетельств того, что знакомство с этой рецензией побудило его заняться изучением самой рецензируемой работы, да еще и первой ее части. Там не менее сам факт такого любопытного совпадения мыслей представляется достойным упоминания. Один из фундаментальных принципов семантики Фреге - что содержание имени имеет две равноправные стороны, смысловую и предметную - был предвосхищен за пятнадцать лет до выхода в свет статьи «О смысле и значении» одним из учеников Брентано.

Что же касается Гуссерля, который, как и Мейнонг, был учеником Брентано, то его знакомство с этим ранним исследованием Мейнонга не является секретом. Обмен идеями между ними был настолько интенсивен, что Мейнонг даже находил поводы для обвинения Гуссерля в плагиате. Хороший сравнительный анализ идей, содержащихся в ранних работах этих двух авторов, можно найти в исследовании К. Иерны [20].

\section{2. Антон Марти: этимон как посредник между знаком и значением}

Антон Марти - один из первых последователей философии Брентано, ставший его учеником еще в Вюрцбургский период. Его шутливо называли министром по делам языка в школе Брентано, и его роль в применении принципов брентанизма к философии языка достаточно хорошо исследована (см., напр.: [21] и приводимую там в примечаниях библиографию). Вместе с тем, кажется, не предпринималось попыток рассмотреть его результаты в контексте становления логической теории именования, в частности в контексте развития соответствующих взглядов Фреге. Здесь мы хотели бы обратить внимание на одну из его ранних работ, «О бессубъектных предложениях и отношении грамматики к логике и психологии», опубликованную в 1884 г., т.е. до появления первых работ по логической семантике, в которой содер-

${ }^{1}$ В 1882 г. Фреге отправлял в этот журнал статью «Булев логический формульный язык и мое понятийное письмо», в 1887-1889 гг. в нем публиковались первые статьи исследования Б. Керри, на содержащиеся в которых критические замечания в свой адрес Фреге отвечал статьей «О понятии и предмете». В этом журнале регулярно публиковались статьи, посвященные логике и философии математики. Поэтому предположение, что он знакомился с публикациями журнала за 1883 и 1884 гг., представляется вполне правдоподобным, тем более что в одной из них, как будет отмечено ниже, благосклонно разбирается одна из его работ. 
жатся основные тезисы его теории языкового значения. Но сначала сделаем несколько замечаний об общем контексте лингвистических исследований, в котором появилась эта статья.

К середине XIX в. в языкознании, как и в логике, установилось доминирование психологизма. Язык рассматривался как порождение и отражение народной либо индивидуальной психологии. Одним из центральных методологических понятий стало введенное В. Гумбольдтом понятие «внутренней формы языка». У Гумбольдта оно было довольно расплывчатым и в дальнейшем получило разнообразные толкования. Сам автор этого термина тесно связывал его смысл с мировоззрением народа, которое находит выражение в его языке. У Х. Штейнталя и М. Лацаруса это привело к разработке этнопсихологии. Здесь внутренняя форма языка рассматривалась как фундамент особого языкового мышления, которое противопоставлялось логическому, или предметному, мышлению, основанному на представлениях. У других исследователей, например у А.А. Потебни, смысл этого термина сдвинулся к внутренней форме слова. Под этим, как правило, подразумевалось этимологическое значение слова. Собственно же проблемы языкового значения не были предметом специализированной рефлексии и находились на периферии лингвистических исследований. Штейнталь и Лацарус, различая понятийное и языковое (или символическое) мышление, настойчиво проводили мысль, что язык - не только средство сообщения, но и средство выражения, оформления мысли. В упомянутой статье Марти излагает и разъясняет некоторые ключевые идеи в форме обширной полемики с этими двумя учеными, а также с В. Вундтом, Х. Зигвартом и др. Одно из центральных положений состоит в том, что даже если допустимо принимать различение этих двух видов мышления, связь между ними не является однозначной. Во всяком случае за понятийно-логическим мышлением следует признать существенную независимость, поскольку логические формы не находят однозначного отражения в формах грамматических; мы не можем познать первые, изучая вторые.

Его аргументация в значительной степени опирается на тезис Брентано, что все суждения, как бы они ни формулировались в естественном языке, являются экзистенциальными. Согласно учению Брентано суждение, будучи действием сознания, надстраиваемым над действием представления, состоит в признании либо отвержении существования представленного предмета. Поэтому для суждения несущественно наличие терминов субъекта и предиката: совершенно не важно, какое количество терминов потребуется для описания принимаемого / отвергаемого предмета представления. Брентано также показал, как все известные логике разновидности суждений можно редуцировать к экзистенциальным [22. С. 49-50]. Марти же интерпретирует технику Брентановских редукций таким образом, что разнообразие других видов суждений, отличных от экзистенциальных, он относит не к логике, но к языку. Это язык устроен так, что позволяет одну и ту же мысль выражать не только экзистенциальным, но и категорическим, и гипотетическим, и каким угодно другим предложением.

Во второй части статьи, где излагаются эти идеи, Марти уделяет четыре страницы обзору фрегевской теории суждения, представленной в «Понятийном письме». Вообще довольно странно, что историки, уделявшие внимание реакции, вызванной этой первой революционной работой Фреге, упустили из 
виду этот отрывок. Ведь это едва ли не единственный из появившихся в первые годы после публикации положительный отзыв, пусть даже он касался только теории суждения и оставил без внимания все остальные идеи Фреге, связанные с логикой и основаниями арифметики.

Марти приветствует не только результат Фреге - освобождение сути суждения от субъектно-предикатного анализа, но и теоретическое основание, которое смогло к этому привести, а именно отделение логики от естественного языка. Как пишет Марти, «попытка освободить мысль от привычных языковых выражений тоже привела его к наблюдению, что между субъектом и предикатом нет логического различия» [23. S. 185]. Действительно, различение в формульном языке Фреге черты содержания и черты суждения совершенно соответствует сути брентановского учения о суждении, которое состоит в отделении содержания, которое утверждается, и самой функции суждения. Есть и два момента в теории Фреге, которые вызывают досаду у Марти. Первый касается того, что Фреге характеризует утверждаемое содержание как «соединение представлений». Марти видит в этом некий пережиток, уступку разоблачаемой теории, показывающую, что Фреге «тоже находится под чарами категорической высказывательной формулы» [Ibid. S. 186]. Второй момент касается того, что Фреге рассматривает отрицание как часть содержания суждения. Для Марти же, который в этом вопросе ни на шаг не отступает от догмы мастера Брентано, утверждение и отрицание представляют собой две равноценные функции суждения. «В высшей степени достойно сожаления, что Фреге не признает в отрицании форму функции суждения, равноценную с утверждением, но рассматривает его как признак утверждаемого содержания (материи)» [Ibid. S. 188]. Заметим также, что не только Марти дал первый положительный отзыв на теорию суждения Фреге, но можно зафиксировать и обратную «симпатию»: логический проект Фреге можно оценить как первое развернутое построение логики, основанное на принципах теории суждения Брентано.

Итак, во второй части статьи Марти использовал открытую Брентано технику сведения всех видов суждений к экзистенциальным, чтобы показать, что понятийное мышление автономно относительно естественного языка. Выделение в структуре суждения субъекта и предиката относится к языковому оформлению суждения, но не касается его логической природы. Вообще категории языка не могут служить основанием для изучения логических категорий, а различения языковых высказываний не должны рассматриваться как различения логических суждений. Поэтому Марти ставит вопрос о том, в чем же тогда состоит и на чем основано различие между разными языковыми выражениями для одного мыслительного содержания. Для ответа на этот вопрос он предлагает в третьей части статьи свою теорию значения и внутренней формы языкового знака, которую он также называет этимоном.

Марти утверждает, что возможность такого различия служит проявлением более общей закономерности. Состоит она в том, что «...сила определенных знаков и их воздействие на душевное состояние слушающего могут быть различными, даже если оба имеют одинаковое значение [Bedeutung] в самом строгом смысле. Имена, которые обозначают одно и то же представление, могут быть внутренне различны» [Ibid. S. 293]. Это внутренне различие и образовано этимоном. Одно и то же представление может обозначаться разными 
словами с разными этимонами. Опережая события, заметим: как тут не впечатлиться, что Марти начинает изложение теории этимона практически с того же вопроса, с которого позднее Фреге начинает изложение теории смысла?

Итак, что же такое, согласно Марти, этимон знака, и как он связан с его значением?

Марти рассматривал язык в первую очередь как средство общения, а не результат выражения народного духа или даже содержаний сознания. Поэтому его теорию значения можно обозначить как «коммуникативную». Как правило, не только упоминавшиеся выше философы, но и многие лингвисты вслед за Локком усматривали значение слова в той идее (представлении), которая ассоциирована с этим словом в сознании говорящего. Согласно же теории Марти, значением [Bedeutung] является представление, которое говорящий желает вызвать в сознании адресата своего сообщения с помощью звучащих знаков. Чтобы достичь этой цели, знак, или внешняя форма слова, должен сначала вызвать некое опосредующее побочное представление [Nebenvorstellung], сопровождающее то представление, которое является собственно значением. Вообще идея о том или ином виде посредничества через побочное вспомогательное представление является одной из ключевых для всего учения Марти и привлекается им неоднократно для объяснения различных родственных феноменов. Для нас наиболее важны два из них, связанные именно со значением. Первый - это посредник между представлением, которое должно быть вызвано в сознании адресата, и представлением в сознании говорящего. Это такое побочное представление, которое всего лишь должно обратить внимание слушающего на сам факт наличия соответствующего представления в сознании говорящего. Второй - посредник между знаком и значением. Именно последний он и называет этимоном.

Словами самого А. Марти, «„Внутренняя языковая форма“, или этимон средства выражения, есть представление, которое служит связующим ассоциативным звеном между внешним воспринимаемым знаком и его значением, т.е. психическим содержанием, которое оно желает возбудить в адресате» [23. S. 298]. Слово, утверждает Марти, способно выполнить эту работу только благодаря тому, что обладает внутренней формой, или этимоном. Но этимон является, если так можно выразиться, более универсальным посредником, чем тот, который мы привели в качестве первого. Он относится к обоим представлениям: и тому, которое есть у говорящего, и тому, которое должно быть возбуждено в слушающем.

В этой связи Марти выделяет две функции знака. Первая из них, та, ради которой знак и используется, - функция обозначения. Хотя она, казалось бы, является главной и целевой, он характеризует ее как вторичную. А вот другую функцию, которая выполняется благодаря этимону, - функцию выявления [Kundgebung], он объявляет первичной.

Этот акцент на первичности опосредующей функции этимона отчасти объясняется тем, что, как я уже упомянул чуть выше, жанровой особенностью этой работы является то, что многие тезисы он формулирует, разъясняет и уточняет в контексте полемики со своими постоянными оппонентами. Сам термин «этимон» как уточнение Гумбольдтовской «внутренней формы» ввел Штейнталь. Он подразумевал под этим изначальное значение слова, которое оно имело в момент появления, «архисему». Но слова меняют значение в 
процессе исторического развития языка, и Штейнталь позволяет понять себя так, что предметом такого изменения является этимон. Как следствие, этимон слова практически отождествляется им с его значением. Во всяком случае Марти именно так понял теорию Штейнталя, и именно за это он его критикует. Марти подхватил у последнего этот термин и при этом обвинил его в том, что тот неправильно понял, в чем на самом деле состоит суть этимона. Хотя автор анализируемой нами статьи тоже видит в этимоне нечто близкое по смыслу к изначальной этимологии, он категорически настаивает на недопустимости смешения этимона слова с его значением. Основной акцент при анализе этимона Марти делает на его опосредующей функции. Статья и завершается провозглашением этого тезиса: «Внутренняя языковая форма не является ни обозначенной мыслью, ни ее органом, но это просто... вспомогательное средство рассудка» [23. S. 340].

Изложение Марти не создает полной ясности относительно онтологического статуса этимона. Он называет этимон «голым представлением» в том смысле, что он не содержится ни в чьем индивидуальном сознании. Но где его собственная сфера пребывания, остается неясным. Он является посредником не между представлениями говорящего и слушающего, но прежде всего посредником между знаком и значением. Вместе с тем, за счет чего осуществляется это посредничество, тоже не вполне ясно. Наконец, пути, способы и конечные пункты опосредования понимаются автором статьи очень широко, но без проникновения в подробности. Как пишет сам автор, «этимон опосредует, там где это вообще требуется, каждый способ, которым языковое выражение является знаком, а также его выявляющую функцию» [Ibid. S. 303]. Как и за счет чего этимон все это выполняет, понять затруднительно.

Другой особенностью теории Марти является то, что этимоном обладает не всякий знак, но только слова естественного языка, которые однажды неким естественным образом возникли. Остальные знаки могут выполнять обозначающую функцию и без помощи этимона, т.е. прямо и неопосредованно. Во-первых, это врожденные знаки. Например, крик - непосредственный знак боли. Во-вторых, это знаки и слова, вводимые соглашениями, например в науке, для игры и т.п. Они тоже не имеют этимона. Наконец, если бы язык служил исключительно для выражения мысли, если бы он был просто орудием понятийного мышления, то не было бы и никакого повода говорить о его внутренней форме. Так, например, числовые знаки, как он считает, являются прямыми репрезентантами числовых понятий и не могут характеризоваться этимоном.

Наконец, последняя важная особенность, которую нельзя обойти вниманием в связи с интересующей нас темой. Внутренней формой, или этимоном, обладает и высказывание [Aussagen]. Этим термином Марти обозначает произнесенное предложение. Его значением является суждение слушающего, т.е., в соответствии с учением Ф. Брентано, согласие слушающего с тем, что внешний предмет, соответствующий тому представлению, которое есть в сознании говорящего и о котором последний сообщает, действительно существует. В случае суждения также наблюдается, во-первых, посредничество между сознаниями говорящего и слушающего, и, во-вторых, реализуемое этимоном посредничество между предложением и суждением. Благодаря успешному выполнению выявляющей функции адресат моего высказывания 
имеет возможность узнать, как я сужу о предмете. Благодаря успешному выполнению обозначающей функции адресат соглашается с моим суждением.

В теории внутренней языковой формы в том виде, как она изложена Марти в статье «О бессубъектных предложениях...», на мой взгляд, есть и другие неясные и даже противоречивые места. Здесь мы не будем углубляться в анализ этих специфически лингвистических и психологических тонкостей, поскольку не они нас в первую очередь интересуют. Нам интересно заметить некоторые замечательные предвосхищения появившихся позднее логических теорий именования, особенно теории Фреге, в рамках лингвистической теории, основанной на методологии Брентано.

Действительно, если отвлечься от содержательных моментов теории Марти, но остановить внимание на ее структурных свойствах, то можно подытожить следующее.

1. Между языковым знаком и его значением необходимо полагать наличие некого опосредующего звена.

2. Знак имеет две функции, причем обозначающая функция является вторичной и зависит от успеха первичной.

3. Разные знаки с разными опосредующими звеньями могут иметь одинаковое значение.

4. Предложение тоже является знаком, для которого выполняются все предыдущие тезисы

Как нетрудно заметить, все эти тезисы совпадают с тезисами Г. Фреге. Остается добавить, что статья Марти «О бессубъектных предложениях», в которой сформулированы все эти тезисы, была опубликована в том же 1884 г., что и «Основания арифметики» Фреге. В этой работе Фреге нет ни одной из перечисленных идей, но, как мы знаем, именно они образуют ядро семантического учения зрелого Фреге, изложенного в работах 1891-1893 гг. Разумеется, это не может рассматриваться как доказательство влияния Марти на Фреге. Мы видим только некоторые концептуальные совпадения, Фреге никогда не ссылается на Марти в своих работах. Но нельзя не признать, что совпадения эти очень впечатляющи.

Имелись ли между этими двумя мыслителями личные контакты? Опишем внешнюю сторону дела. В Гёттингене в начале 1870-х гг. их жизненные траектории весьма сблизились, но, по всей видимости, личного знакомства между ними так и не случилось. Фреге, отучившись в Гёттингенском университете пять семестров, защитил там докторскую диссертацию по математике в декабре 1873 г., а в мае 1874 г., предварительно защитив уже в Йенском университете хабилитационную работу, приступил там же к чтению лекций. Марти в период обучения Фреге в Гёттингене преподавал философию в лицее в родном Швице, и как раз в мае 1874 г., по примеру своего наставника Брентано отказался от сана священника и лишь после этого, по причине вызванного этим решением скандала, был вынужден оставить не только преподавание, но и Швейцарию. Диссертацию по философии он защитил в Гёттингене под руководством Р.Г. Лотце уже в 1875 г. Марти был дружен с Карлом Штумпфом, вместе с которым посещал лекции Брентано в Вюрцбурге. В свою очередь, Штумпф защитил диссертацию по философии математики в Гёттингене под руководством того же Лотце уже в 1870 г. и после этого до 1873 г. в должности приват-доцента преподавал в том же Гёттингенском уни- 
верситете. Имя Фреге не числится в списке записавшихся на его курс, тем не менее факт их личного знакомства выглядит почти достоверным. Сам тон сохранившихся писем, которыми они обменялись в 1882 г., заставляет думать, что мы имеем дело с коммуникацией людей, которые лично общались до того, как начали писать письма друг другу. В переписке Фреге, изданной в 1969 г., письмо от 29 августа 1882 г. идентифицировано как письмо, адресованное А. Марти. Однако в ходе дальнейших исследований достаточно убедительно показано, что на самом деле его адресатом следует считать К. Штумпфа и что письмо последнего к Фреге от 9 сентября 1882 г. было ответом именно на первое. Словом, Марти и Фреге, скорее всего, не были знакомы ни лично, ни по переписке. Но оба были в довольно тесных и доверительных (а Марти - в дружеских) отношениях со Штумпфом. Будучи ровесниками и находясь в несовпадающие буквально временные промежутки, но в один и тот же исторический период в Гёттингенском университете, они имели сильно пересекающиеся круги общения и испытывали одинаковые интеллектуальные влияния - достаточно упомянуть Р.Г. Лотце и К. Штумпфа. В отличие от описанного выше случая Фреге и Мейнонга, который только говорит о слабой возможности наличия между ними интеллектуальной связи, в случае Фреге и Марти вероятность подобной связи выглядит очень высокой.

\section{Заключение}

Теории именования, разработанные немецкими логиками, которые легли в основание одного из разделов современной логической семантики, появились во многом благодаря своеобразному забвению старых теорий сигнификации, развивавшихся в Британской философии Нового Времени. Это частичное забвение старого, или, если угодно, его растворение в новом, произошло в ходе нескольких взаимосвязанных процессов. Во-первых, эти Британские теории были модернизированы при переносе в английскую логику в первой половине XIX в. Уэтли и Миллем. Во-вторых, они претерпели смысловые сдвиги в базисной терминологии при переводе на немецкий язык. В третьих, некоторые из их фундаментальных принципов были переинтерпретированы в терминах, привычных для немецкоязычной логики и философии, но чуждых для Британской традиции. Наконец, как мы пытались показать, очень вероятно, что они были соединены с другими идеями, самостоятельно развивавшимися в школе Брентано и немецком языкознании. За рамками представленного здесь исследования остался анализ того, какие из перечисленных процессов и в каких формах нашли отражение в построениях Шрёдера, Гуссерля и Фреге. Последняя тема, безусловно, заслуживает отдельного внимания.

\section{Лumepamypa}

1. Dawson: Locke, Language and Early-Modern Philosophy. Cambridge : Cambridge University Press, 2007.

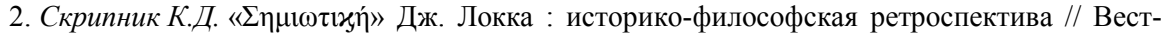
ник Пермского университета. Философия. Психология. Социология. 2017. Вып. 2. С. 172-182.

3. Черноскутов Ю.Ю. Развитие семантических идей в Британской логике XIX века // Paцио.ru. 2016. № 2 (17). С. 111-133. 
4. Черноскутов Ю.Ю. Язык и предмет логики в Британской логической традиции ХІХ века // Вестник Санкт-Петербургского университета. Сер. 6. Философия. Культурология. Политология. Право. Международные отношения. 2012. № 1. С. 3-15.

5. Whately $R$. Elements of Logic. From the $8^{\text {th }}$ London ed. revised. New York : Harper \& Brothers, $1855.396 \mathrm{p}$.

6. Whately R. Elements of Logic. London : Printed for J. Mawman, 1827. 348 p.

7. Уэтли Р. Основания логики. СПб. : Изд. А.В. Заленского, 1873. 547 с.

8. Mill J.S. A System of Logic, Ratiocinative and Inductive. London : J.V. Parker, 1843. Vol. 1. $580 \mathrm{p}$.

9. Милль Дж.С. Система логики : в 2 т. СПб. : Изд. М.О. Вольфа, 1865. Т. 1. 553 с.

10. Mill J.S. System der deduktiven und inductiven Logik / Übersetzt von J. Schiel. Braunschweig : Friedrich Vieweg und Sohn, 1868. Bd. 1.

11. Fischer K. Francis Bacon und seine Nachfolger. Entwicklungsgeschichte der Erfahrungsphilosophie. Leipzig : F.U. Brockhaus, 1875. 788 S.

12. Barber K. Meinong's Hume studies. Part I: Meinong's Nominalism // Philosophy and Phenomenological Research. 1970. Vol. 30, № 4. P. 550-567.

13. Barber K. Meinong's Hume studies II: Meinong's Analysis of Relations // Philosophy and Phenomenological Research. 1971. Vol. 31, № 4. P. 564-584.

14. Rollinger R.D. Meinong and Husserl on Abstraction and Universals: From Hume Studies I to Logical Investigations II. Amsterdam-Atlanta : Rodopi, 1993. 196 p.

15. Локк Дж. Опыт о человеческом разумении // Сочинения : в 3 т. М., 1985.

16. Meinong A. Hume Studien I. Zur Geschichte und Kritik des modernen Nominalismus // Sitzungsbereiche der phil.-hist. Classe der kais. Akademie der Wissenschaften. 1877. Bd. 78. S. 185-260.

17. Frege G. Grundlagen der Arithmetik. Hamburg : F.Meiner, 1986.

18. Meinong A. Hume Studien II. Zur Relationstheorie // Sitzungsbereiche der phil.-hist. Classe der kais. Akademie der Wissenschaften. 1882. Bd. 101. S. 573-752.

19. Höffler A. Meinong, Alexius. Hume-Studien I... Anzeige // Vierteljahrsschrift für wissenschaftliche Philosophie. 1883. Bd. 7. S. 482-491.

20. Ierna K. Relations in the early Works of Meinong and Husserl // Meinong studies. 2009. Vol. 3. P. 7-36.

21. Громов P.A. Антон Марти. Философия языка Брентановской школы // Логос 19912005. Избранное. М. : Территория будущего, 2006. Т. 1. С. 197-235.

22. Черноскутов Ю.Ю. Ф. Брентано: опыт реформирования силлогистики // Логикофилософские штудии. 2010. № 8. С. 46-53.

23. Marty A. Ueber subjectlose Sätze und das Verhältniss der Grammatik zu Logik und Psychologie // Vierteljahrsschrift für wissenschaftliche Philosophie. 1884. Bd. 8, Art. 1. S. 56-94; Art. 2. S. 161-192; Art. 3. S. 292-340.

Jurij Ju. Chernoskutov, Saint Petersburg State University (Saint Petersburg, Russian Federation). E-mail: chernoskutov@mail.ru; ju.chernoskutov@spbu.ru

Vestnik Tomskogo gosudarstvennogo universiteta. Filosofiya. Sotsiologiya. Politologiya-Tomsk State University Journal of Philosophy, Sociology and Political Science. 2019. 50. pp. 117-136.

DOI: $10.17223 / 1998863 \mathrm{X} / 50 / 12$

DEVELOPMENT OF THEORETICAL AND TERMINOLOGICAL FOUNDATIONS OF SEMANTICS IN THE LOGIC AND PHILOSOPHY OF THE 21st CENTURY

Keywords: signification; meaning; Whately; Mill; Meinong; Marty; Frege.

The article traces some principal points of the history of the development of terms and conceptions which served as the basis for German logical doctrines of semantics in the 1890s. The first part of the article considers the theory of signification inside English logic and the deformations it underwent when translated into German. Semantic issues were part of logic in the British tradition because the latter used to view the subject of logic as a reasoning, and language as the only bearer of that reasoning. In addition, the theory of signification was an important part of British modern philosophy. These approaches were incorporated into logic by Richard Whately, but with some modifications. He in fact reduced signification to denotation and, in order to explicate the nature of common names, introduced the notion of class into logic. It was John Stuart Mill who explicitly developed the logical theory of signification. He did not share Whately's radical nominalism and founded his theory not on class, but on the distinction of two kinds of signification: denotation, or direct way of representing an object, and connotation, which does the same work indirectly, via attributes. Along with signification, he intro- 
duced the concept of meaning into logic. When Mill's and classical British philosophers' works were translated into German, some terminological shifts crept in. The difference between signification and meaning disappeared in the German text of Mill's Logic, and between signification and denotation in the German translation of Berkeley. The second part of the article considers some treatments of the name theory in the school of Brentano. On the material of Meinong's doctoral thesis of 1877, the author traces how British issues were adapted in continental philosophy. Namely, he tries to intepret the British discussion of abstract ideas in terms of "Inhalt" and "Umfang", which were alien for British logic and philosophy. As a consequence, he came to a conclusion principally foreign for the latter: object and idea should be viewed as different sides of signification. On the material of Anton Marty's article on subjectless propositions, published in 1884, the author attracts attention to the possible influence of linguistic theories of meaning on the logical semantic theories. The principal idea of Marty's doctrine is that of a need in a mediating link between a sign and its meaning which he called "etymon". He describes the meaning as a secondary function of a sign while an etymon as a primary one. Different words with different etymons can have the same meaning. The sentence is a kind of a name; consequently, it has an etymon as well. Thus, there is an evident formal correspondence between Frege's logical semantics and Marty's linguistic semantics. Finally, the author gives some arguments for the idea that Frege was acquainted with the considered ideas of Meinong and Marty.

\section{References}

1. Dawson, H. (2007) Locke, Language and Early-Modern Philosophy. Cambridge: Cambridge University Press.

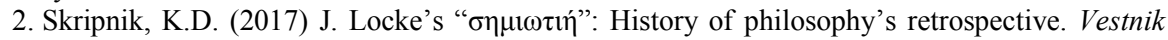
Permskogo universiteta. Filosofiya. Psikhologiya. Sotsiologiya-Perm University Herald. Series "Philosophy. Psychology. Sociology”. 2. pp. 172-182. (In Russian). DOI: 10.17072/2078-7898/2017-2172-182

3. Chernoskutov, Yu.Yu. (2016) The Development of Semantic Ideas in the British Logic of 19th Century. Ratsio.ru. 2(17). pp. 111-133. (In Russian).

4. Chernoskutov, Yu.Yu. (2012) Yazyk i predmet logiki v Britanskoy logicheskoy traditsii XIX veka [Language and the subject of logic in the British logical tradition of the 19th century]. Vestnik Sankt-peterburgskogo universiteta. Seriya 6: Filosofiya. Kul'turologiya. Poli-tologiya. Pravo. Mezhdunarodnye otnosheniya. 1. pp. 3-15.

5. Whately, R. (1855) Elements of Logic. From the 8th London ed. revised. New York: Harper \& Brothers.

6. Whately, R. (1827) Elements of Logic. London: Printed for J. Mawman.

7. Whately, R. (1873) Osnovaniya logiki [Elements of Logic]. Translated from English. St. Petersburg: A.V. Zalensky.

8. Mill, J.S. (1843) A System of Logic, Ratiocinative and Inductive. Vol. 1. London: J.V. Parker.

9. Mill, J.S. (1865) Sistema logiki: v 2 t. [A System of Logic. In 2 vols]. Translated from English. Vol. 1. St. Petersburg: M.O. Wolf.

10. Mill, J.S. (1868) System der deduktiven und inductiven Logik. Vol.1. Braunschweig: Friedrich Vieweg und Sohn.

11. Fischer, K. (1875) Francis Bacon und seine Nachfolger. Entwicklungsgeschichte der Erfahrungsphilosophie. Leipzig: F.U. Brockhaus.

12. Barber, K. (1970) Meinong's Hume studies. Part I: Meinong's Nominalism. Philosophy and Phenomenological Research. 30(4). pp. 550-567.

13. Barber, K. (1971) Meinong’s Hume studies II: Meinong's Analysis of Relations. Philosophy and Phenomenological Research. 31(4). pp. 564-584.

14. Rollinger, R.D. (1993) Meinong and Husserl on Abstraction and Universals: From Hume Studies I to Logical Investigations II. Amsterdam-Atlanta: Rodopi.

15. Locke, J. (1985) Sochineniya: $v 3$ t. [Works. In 3 vols]. Translated from English. Moscow: Mysl'.

16. Meinong, A. (1877) Hume Studien I. Zur Geschichte und Kritik des modernen Nominalismus. Sitzungsbereiche der phil.-hist. Classe der kais. Akademie der Wissenschaften. 78. pp. 185-260.

17. Frege, G. (1986) Grundlagen der Arithmetik. Hamburg: F. Meiner.

18. Meinong, A. (1882) Hume Studien II. Zur Relationstheorie. Sitzungsbereiche der phil.-hist. Classe der kais. Akademie der Wissenschaften. 101. pp. 573-752.

19. Höffler, A. (1883) Meinong, Alexius. Hume-Studien I... Anzeige. Vierteljahrsschrift für wissenschaftliche Philosophie. 7. pp. 482-491. 
20. Ierna, K. (2009) Relations in the early Works of Meinong and Husserl. Meinong Studies. 3. pp. 7-36.

21. Gromov, R.A. (2006) Anton Marti. Filosofiya yazyka Brentanovskoy shkoly [Anton Marty. Philosophy of the language of the Brentano School]. In: Anashvili, V.V. \& Pogorelsky, A.L. (eds) Logos 1991-2005. Izbrannoe [Logos 1991-2005. Selected Works]. Vol. 1. Moscow: Territoriya budushchego. pp. 197-235.

22. Chernoskutov, Yu.Yu. (2010) F. Brentano: opyt reformirovaniya sillogistiki [F. Brentano: on reforming syllogistics]. Logiko-filosofskie shtudii. 8. pp. 46-53.

23. Marty, A. (1884) Ueber subjectlose Sätze und das Verhältniss der Grammatik zu Logik und Psychologie. Vierteljahrsschrift für wissenschaftliche Philosophie. 8. pp. 56-94. 